\title{
Kinematic Cooperative Optimization Control Algorithm for Underground Heavy-Load Robot
}

\author{
Lixia Fang ${ }^{1,2}$ (I) $\cdot$ Tong Wang $^{2} \cdot$ Pengjiang Wang ${ }^{1} \cdot$ Chenxin Hou ${ }^{1} \cdot$ Miao $\mathrm{Wu}^{1}$
}

Received: 28 April 2020 / Accepted: 1 March 2021 / Published online: 19 April 2021

(C) The Author(s) 2021

\begin{abstract}
Because of complex and strong coupling system, the precision and adaptability of underground robots are greatly restricted. Based on the newly developed intelligent underground heavy-load robot which is still a gap to fill in current coal mine machinery, this paper proposes a new dynamic cooperative optimization control algorithm. Firstly, the complex and strongly coupled Multidisciplinary Design Optimization system of the robot is decoupled into horizontal/vertical motion space with the idea of hierarchical target transmission, in order to weaken the strong coupling relationship between each hydraulic loop. Then, the spatial posture coefficient is introduced into main/auxiliary feedback control loop in horizontal/vertical motion space, to realize optimal collaborative control of each hydraulic loop under the premise of weak coupling between each control loop, so as to obtain the precise dynamic control signals of each hydraulic loop, and finally realize the optimal control of overall system for the robot. Lastly, the experiment and simulation verify that the DCO control algorithm presented in this paper can obtain better control results: The executive efficiency of the overall system is improved by $14.2 \%$; The control flow is saved by $9.98 \%$, and the executive precision meets the engineering and technical requirements. This paper provides a new efficient method and idea for the control system of intelligent underground heavy-load robots. Furthermore, the algorithm has reference value on development and design of high precise control system for the same kind of complex intelligent engineering machinery products.
\end{abstract}

Keywords Intelligent underground heavy-load robot · Complex MDO system · Dynamic collaborative optimization · Hierarchical target transmission $\cdot$ Spatial posture coefficient

\section{Introduction}

Nowadays, coal has always been a major source of energy in China. According to China National Energy Administration, the total output of raw coal stood at 3.52 billion tons in 2019, $90 \%$ of which entirely depended on underground excavation. In addition, $40 \%$ of mines are more than $500 \mathrm{~m}$ below the surface. Over 40 mines extend up to more than one kilometer, and prolong to deeper at speed of 8-12 m per year (http:// paper.people.com.cn/zgnyb/html/2019-8-19/content_ 1942517.htm). Deep, long-distance and large-span tunnel

Pengjiang Wang

53263898@qq.com

1 School of Mechanical Electronic and Information Engineering, China University of Mining and Technology (Beijing), Beijing 100083, China

2 School of Information and Engineering, China University of Mining and Technology Yinchuan College, Yinchuan 750011, China digging becomes a technological difficulty for China's coal mining to be intelligent, efficient and safe, which also becomes the leading-edge technology of international tunnel field. Meanwhile, with the increase of digging depth, the further deterioration of underground environment condition has greatly slowed down the process of underground coal mining. Therefore, a new intelligent robot technology becomes a core research for coal mining machinery [1]. For the above reasons, a new type of intelligent heavy-load tunnel robot is developed (hereinafter referred as underground heavy-load robot). It has a ability to complete over two tons of heavy-load work (such as transporting, hoisting and supporting), and can be used in tunnels and chambers under the conditions of narrow, airtight, low illumination, damp and high risk (such as tunnel floor heave, collapse and so on). Because of the advantages of flexibility, heavy-load carrying, multi-function and fast response, it also can be applied to the emergency rescue occasions of underground and similar circumstances. The underground heavy-load robot fills a gap of intelligent underground heavy-load robots in China, and even provides a guarantee 
for the safe and efficient production of underground coal mining technology and highway industry.

The new developed underground heavy-load robot is a typical kind of complex Multi-disciplinary Design Optimization (MDO) engineering product which is strongly coupled by mechanical, electrical and hydraulic systems [1, 2]. If adopting traditional design methods, the final design results are incapable of reaching optimum performance of the integrated robot system for ignoring the strong coupling relationship among different disciplines. Therefore, scholars have made some researches on the design of MDO control system: [3] optimized the complex MDO mechanical system of a four-roller rolling mill by applying collaborative optimization method. [4] put forward a collaborative optimization algorithm by transforming the constrained optimization problems into unconstrained optimization problems, and applied it to the design of oil tanker. [5] made full use of random control, and proposed a two-level multi-objective cooperative optimization method based on genetic algorithm of MDO framework for UAV. [6] adopted Monte Carlo method to simulate the compound impact of parameters and modeled the uncertainties, then applied MRDO-UPM framework to design a reducer and a liquid cooling battery thermal management system. In [7], the MDO was applied to integrate the aircraft modeling technology, sensitivity analysis technology, optimization algorithm, surrogate model technology and other key technologies. [8] applied MDO technology to the structure design of automobile body and chassis, effectively solved the multi-disciplinary and multi-objective optimization problems, especially for engineering optimization problems with diverse design variables and optimization objectives. [9] made use of MDO to optimize the six geometric structure parameters of pump, output the optimal shaft power parameters, and obtained the influence of coupling effect of geometric parameters on hydraulic performance of pump, thus effectively balanced the design requirements of complex hydraulic pump.

Most of these researches on complex MDO systems are limited to the improvement of structural performance under the conditions that all kinds of constraints (such as product modeling, structure design and process plan) are satisfied [10]. Nevertheless, the dynamic control problem should also be collaboratively considered during the design of complex MDO systems.

Therefore, based on the above researches, this paper takes the complex system of the underground heavy-load robot as carrier, and presents a new dynamic collaborative optimization (DCO) control algorithm, which considers the executive system, control system and mechanical structure in parallel and collaboratively, and achieves the efficient design of whole MDO control system for the robot. The DCO algorithm presented in this paper can not only meet the requirement of optimal structural design, but also satisfy the precise control requirements of intelligent robots.

The structure of this article is shown as Fig.1.

The underground heavy-load robot is composed of mechanical body, hydraulic control system, and electrical control system etc. It can be used to complete much complex heavyload work flexibly and quickly which is difficult to finish by ordinary industrial heavy-load robots for the narrow, small, dangerous circumstance and under tunnel explosion-proof requirements. Meanwhile, with a load of more than $2 \mathrm{kn}$ and $700 \mathrm{~J}$ impact resistance, the robot can easily complete the non-fixed point heavy-load work such as grabbing, loading and supporting etc. In the meantime, it can effectively repair the deformation of underground coal/rock caused by ground pressure and other factors [11]. Therefore the underground heavy-load robot will play a positive role in promoting development for the control technology of underground, ensuring
Fig. 1 The flow chart of DCO control for the underground heavy-load robot

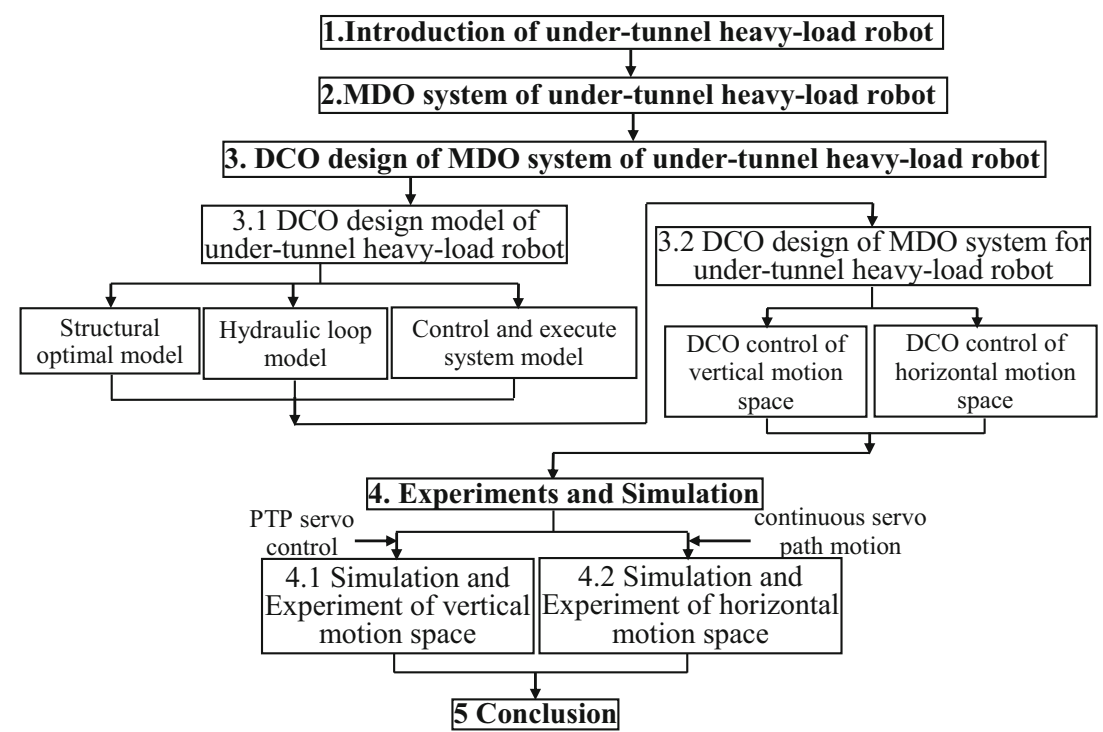


safe and efficient production of underground coal mining technology and highway industry [12].

The 5-DOF (Degree of Freedom) underground heavy-load robot is formed of four parts: The first part is a walking mechanism: including crawler, fuselage and sprocket etc., which can realize movement of the robot at the bottom of tunnel with the condition of uneven, soft and muddy ground at the speed of $27 \mathrm{~m} / \mathrm{min}$. The second part is a lifting and rotating mechanism, which can realize the whole executive arm to move up and down along vertical direction by $230 \mathrm{~mm}$, swing around the central axis of turntable by $\pm 40^{\circ}$ and rotate along the center of swivel arm by $\pm 180^{\circ}$. The third part is an actuator arms mechanism consisted by three actuator arms and a quick change device. The fourth part is the final output actuator, which can complete various underground heavy-load jobs by replacing different actuators (crushing hammer, milling head, hydraulic shear, etc.). This is another special characteristic of underground heavy-load robot that can achieve one machine with multi-functions. The prototype and control system of the underground heavy-load robot are shown in Fig. 2.

\section{MDO System of the Underground Heavy-Load Robot}

The design of the underground heavy-load robot involves many disciplines, including mechanical mechanism, mechanism kinematics, mechanism dynamics, hydraulic, electrical and intelligent control etc. Therefore, it belongs to a typical multi-disciplinary design as shown in Fig. 3.

Up to now, multidisciplinary design optimization (MDO) is the most effective theoretical technology for life-cycle design of products in modern manufacturing. The control algorithms for complex MDO system involve: Single level optimization (SLO) algorithm based on sensitivity, parallel subspace optimization (PSO) algorithm and collaborative optimization (CO) algorithm $[13,14]$. "Parallelism" and "collaboration" have become the core technologies to achieve the optimal design of MDO system. That is, to shorten the design cycle by completing the design of each discipline in parallel.
Meanwhile, to ensure the design quality by making rational and effective use of disciplines and cooperating the relationship among disciplines effectively, finally to obtain the optimal design of overall system. Therefore, this paper proposes a dynamic collaborative optimization (DCO) control algorithm to solve the above problems effectively by considering the actual operation process of each discipline dynamically, interactively and coordinately.

\section{DCO Design of MDO System for Underground Heavy-Load Robot}

Based on the above analysis, to realize the efficient and optimal design of the whole MDO system for the underground heavyload robot, the DCO design of MDO system for the robot will be implemented in mechanical structure, hydraulic loops control and the whole control/executive system respectively.

\subsection{DCO Design Model of Underground Heavy-Load Robot}

\subsubsection{Structural Optimal Model}

Taking the spatial output trajectory of the executive end as final control parameter, the high precision control of executive end can be achieved through coordinating the actions of each actuator efficiently. The structural sketch of the underground heavy-load robot is shown in Fig. 3.

In Fig. 4: $i$ is the hydraulic loop $(i=1,2,3 \ldots 6$, represents the lifting platform hydraulic loop, swinging hydraulic loop, rotating hydraulic loop, big-arm hydraulic loop, small-arm hydraulic loop and executive end hydraulic loop respectively) and 7 is the output actuator. A,B,C are the hinge points of the adjacent hydraulic loops. $\mathrm{O}-\mathrm{XYZ}$ is the coordinate system of the underground heavy-load robot.

Assuming the transient spatial posture of the executive end is $\mathrm{W}, \mathrm{W}=[\mathrm{X}, \mathrm{Y}, \mathrm{Z}, \alpha, \beta, \gamma]^{\mathrm{T}}$ (where: $[\mathrm{X}, \mathrm{Y}, \mathrm{Z}]^{\mathrm{T}}$ is the spatial location $(\mathrm{mm}) ;[\alpha, \beta, \gamma]^{\mathrm{T}}$ are the spatial angles $\left.\left({ }^{\circ}\right)\right)$. $\mathrm{Y}(\mathrm{X})$, $\mathrm{Y}(\mathrm{Y})$ and $\mathrm{Y}(\mathrm{Z})$ are the spatial output displacement functions
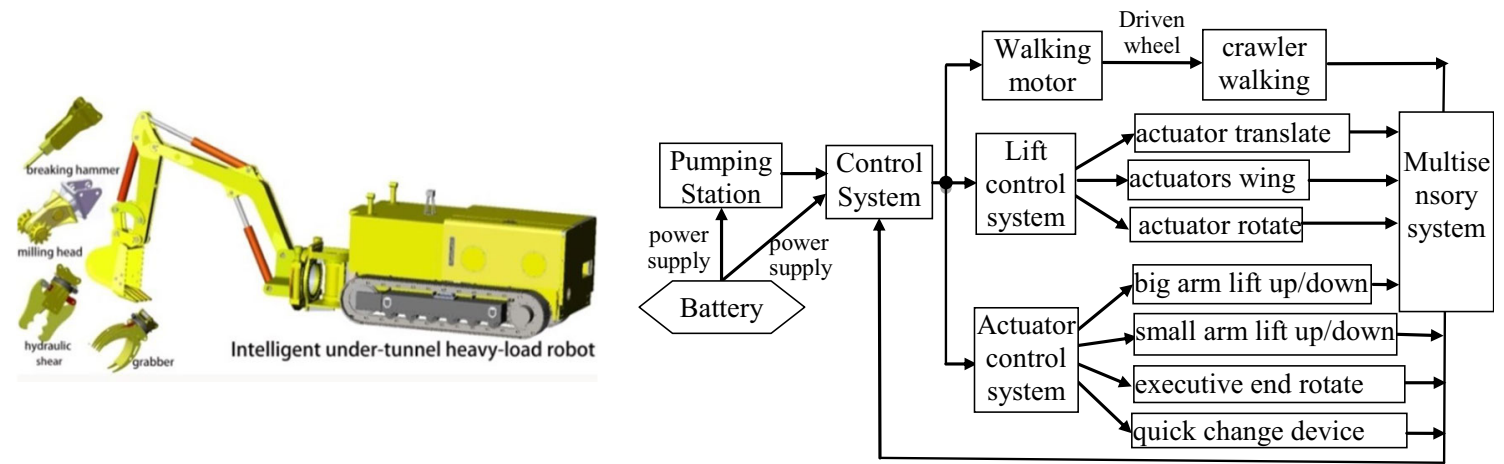

Fig. 2 The prototype and control system of underground heavy-load robot 


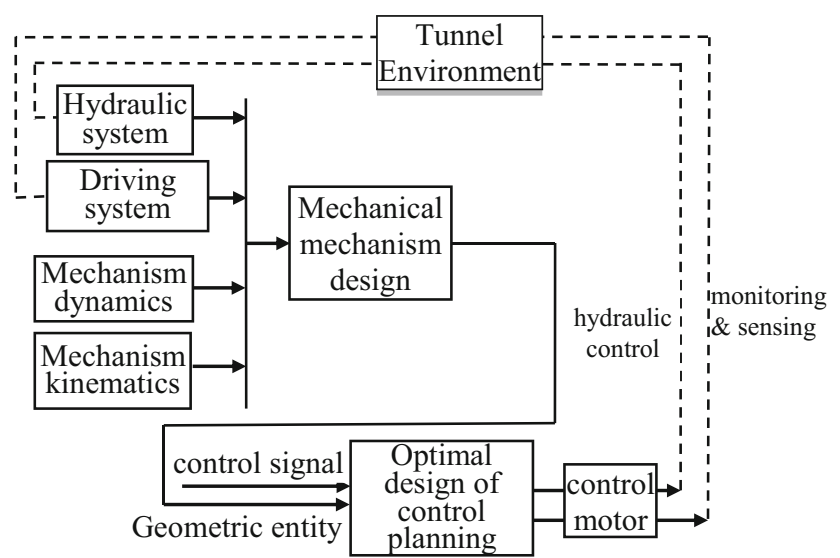

Fig. 3 MDO system of underground heavy-load robot

along $\mathrm{X}, \mathrm{Y}, \mathrm{Z}$ direction respectively; $\mathrm{Y}(\alpha), \mathrm{Y}(\beta)$ and $\mathrm{Y}(\gamma)$ are the horizontal angle, pitch angle and rolling angle functions of the executive end respectively.

Lagrange equation of the underground heavy-load robot can be established according to the dynamic mechanical system [15] as Eq.(1).

$\frac{d}{d t}\left(\frac{\partial T}{\partial \dot{q}_{i}}\right)-\frac{\partial T}{\partial q_{i}}+\frac{\partial D}{\partial \dot{q}_{i}}+\frac{\partial V}{\partial q_{i}}=Q_{i}(t)$

Where $t$ is the working time of the robot; $q_{\mathrm{i}}$ and $Q_{\mathrm{i}}$ are the generalized coordinates and generalized force. $T$ is the total kinetic energy of the system; $V$ is the total potential energy and $D$ is the dissipation function of the system.

Thus DCO optimal structural design model of the underground heavy-load robot is shown as Eq.(2) .

$\min .\left\{\begin{array}{l}\sum W=\sum Y_{i}(X, Y, Z, \alpha, \beta, \gamma)-\sum \widehat{Y}_{i}(X, Y, Z, \alpha, \beta, \gamma) \\ \sum t=t_{1}+t_{2}+t_{3}+t_{4}+t_{5}+t_{6} \\ \sum Q=Q_{1}+Q_{2}+Q_{3}+Q_{4}+Q_{5}+Q_{6}\end{array}\right.$

The geometric structural constraints are:

\footnotetext{
$\left(Y_{1}(Z) \in[0,230]\right.$

$Y_{2}(\alpha) \in\left[-40^{\circ}, 40^{\circ}\right]$

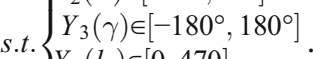

$\left\{Y_{4}\left(l_{4}\right) \in[0,470]\right.$

$Y_{5}\left(l_{5}\right) \in[0,540]$

$Y_{6}\left(l_{6}\right) \in[0,470]$
}

Fig. 4 DCO model of underground heavy-load robot
And the digging constraints are: s.t. $\left\{\begin{array}{l}w_{2}(\alpha) \leq 0.0009813 \\ v \leq 27 \\ f \leq 500\end{array}\right.$

In the DCO structural optimization model (2): $Y_{i}(\mathrm{X}, \mathrm{Y}$, $\mathrm{Z}, \alpha, \beta, \gamma)$ is the actual spatial posture of the executive end and $\widehat{Y}_{i}(\mathrm{X}, \mathrm{Y}, \mathrm{Z}, \alpha, \beta, \gamma)$ is the planned spatial posture of the executive end. $\sum t$ is the total working time; $t_{i}$ is the executive time of each executive loop. $\sum Q$ is the total control flow of the hydraulic system and $Q_{i}$ is the control flow of each executive hydraulic loop $(i=1,2,3,4,5,6)$.

In the geometric constraint model: $Y_{i}\left(l_{i}\right)$ is the displacement function of each hydraulic control loop $(i=1,2,3,4,5,6) . Y_{2}(\alpha)$ is the horizontal swing angle function of swinging hydraulic loop 2. $Y_{3}(\gamma)$ is the roll angle function of rotating hydraulic loop 3. $w_{2}(\alpha)$ is the swing angle speed $(\mathrm{rad} / \mathrm{s}) ; v$ is the walking speed of the robot $(\mathrm{m} / \mathrm{min}) . f$ is the impacting frequency of the executive end $(\mathrm{bpm})$.

In the DCO structural optimal model of MDO system for the underground heavy-load robot, the geometric structural constraints and dynamic driving constraints of the whole system are considered in parallel, which makes the optimal model more close to the actual prototype.

\subsubsection{Hydraulic Loop Model}

The underground heavy-load robot adopts diesel engine as main power, utilizes hydraulic pump to control each hydraulic loop against load/loss and execute actions. Therefore, the precondition to realize optimal matching of power in the whole MDO system of the robot is cooperating the flow of each hydraulic loop efficiently [15]. Related researches show that the friction in hydraulic control system (between piston and hydraulic cylinder, piston rod and hydraulic oil, etc.) accounts for $1 \% \sim 10 \%$ of total driving torque. Thus to achieve the precise control of the whole system, the friction in the hydraulic system cannot be ignored. The total friction $\sum F_{\mathrm{f}}$ in hydraulic loops of the robot can be calculated [16] as:

$\sum F_{f}=\left\{\begin{array}{l}\left(F_{c}+F_{v}\right) * \operatorname{sgn}\left(v_{r}\right), v_{r} \neq 0 \\ F_{s}, v_{r}=0\end{array}\right.$

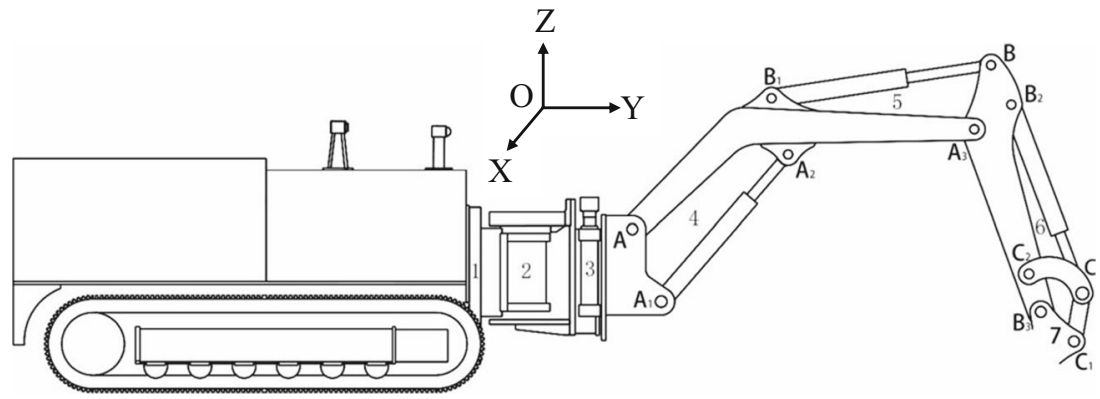


Where: $v_{\mathrm{r}}$ is the moving speed of piston in single hydraulic loop $(\mathrm{m} / \mathrm{s}) ; F_{\mathrm{c}}$ is the Coulomb friction $(N) ; F_{\mathrm{v}}$ is the viscosity friction of hydraulic oil $(N) ; F_{\mathrm{s}}$ is the static friction between hydraulic piston and cylinder $(N)$.

Since the executive hydraulic control loops of the heavyload robot are connected in parallel, the displacement model of single hydraulic control loop is shown as Eq. (4) .

$$
\Delta l_{i}(s)=\frac{K_{q} s(t)-\frac{K_{p}}{A} F_{L_{i}}(s)}{\frac{K_{p} M}{A} s^{2}+\left(\frac{K_{p} \sum F_{f}}{A}+A\right) s}
$$

Where: $\Delta l_{i}$ is the output displacement of each hydraulic control loop $(\mathrm{mm}) . s_{i}(t)$ is the transformation function of a single hydraulic loop $(i=1,2,3,4,5,6) . M$ is the total mass of a single hydraulic control loop $(\mathrm{kg})$.

$K_{p} \quad$ is the flow variation coefficient of hydraulic loop: $K_{p}$

$$
=\frac{\partial Q_{i}}{\partial P}=\frac{C_{q} \Delta w_{s}(\Delta l)}{\sqrt{2 \rho \Delta P}}
$$

$F_{L i} \quad$ is the external load of piston rod in hydraulic loop $(N)$

$A \quad$ is the area without rod cavity in single hydraulic loop $\left(\mathrm{mm}^{2}\right)$

$K_{q} \quad$ is the flow change coefficient of hydraulic loop: $K_{q}$

$=\frac{\partial Q_{i}}{\partial s}=C_{q} \Delta w_{s} \sqrt{\frac{2}{\rho} \Delta P}$

$\Delta w_{s}$ is the gradient change of valve at inlet and outlet of hydraulic loop $(m)$;

$\rho \quad$ is the density of hydraulic oil $\left(865 \mathrm{~kg} / \mathrm{m}^{3}\right)$;

$\Delta \mathrm{P} \quad$ is the pressure change at inlet and outlet of hydraulic loop $(M P a)$.

For existence of friction and loss in the hydraulic loops, it is difficult to achieve the real-time precise control of all hydraulic loops. However the output displacement $\Delta l_{i}$ of each hydraulic loop can be measured easily by built-in displacement sensor, thus the corresponding control flow $Q_{i}$ of each hydraulic loop can be deduced by Eq. (4) reversely. Then the control flow of each hydraulic loop can be coordinated and optimized according to the planned trajectory of the actuator, finally to realize the efficient coordinate control of overall hydraulic system.

\subsubsection{Control and Execute System Model}

According to the structural analysis, we can conclude that the final output of the underground heavy-load robot is strongly coupled by executive and hydraulic control loops, especially when the robot performs compound actions. The schematic diagram is shown in Fig. 5.

In Fig. 5: $Y_{i}\left(l_{i}\right)$ are the input control signals of the hydraulic loops. $E_{i}\left(l_{i}\right)$ are the expected control signals of the hydraulic loops. $C_{i}(X, Y, Z, \alpha, \beta, \gamma)$ are the actual control signals of the

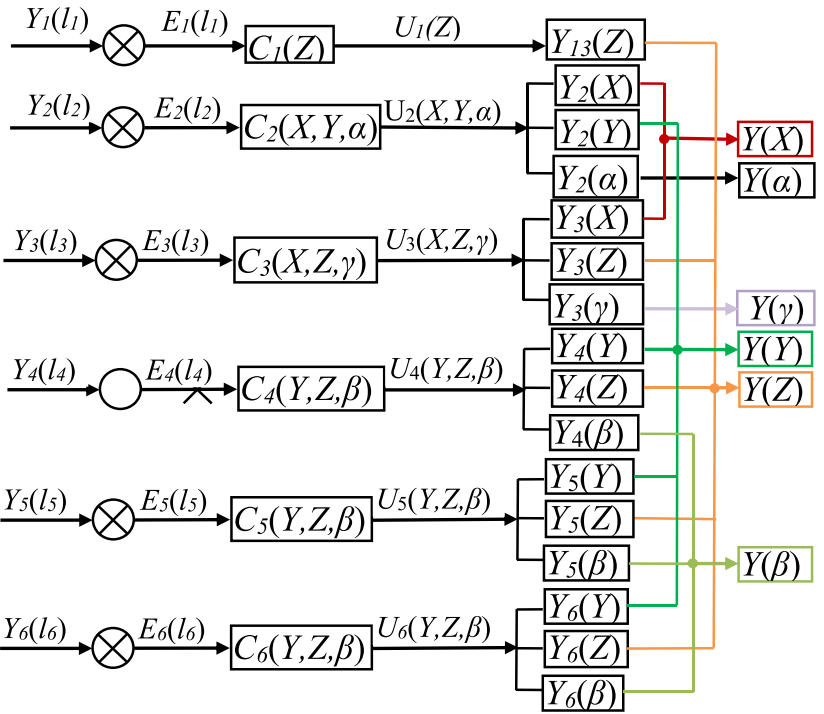

Fig. 5 Control schematic diagram of underground heavy-load robot

hydraulic loops. $U_{\mathrm{i}}(X, Y, Z, \alpha, \beta, \gamma)$ are the output control signals; $Y_{i}(X, Y, Z, \alpha, \beta, \gamma)$ is the actual output posture function of hydraulic loop $i ; Y(X, Y, Z, \alpha, \beta, \gamma)$ is the finally output posture function of executive end. $(i=1,2,3, \ldots . .6)$

Figure 5 shows that the output spatial posture of the executive end is strongly coupled by the complex hydraulic loops, thus the precise output posture of the robot can be achieved by coordinating the corresponding hydraulic loops reasonably. In the end the relationship between hydraulic loops and output pitching angle of the executive end is simulated in Fig. 6(a), and the corresponding relationships between hydraulic loops and $\mathrm{Y} / \mathrm{Z}$ direction posture of the executive end are simulated in Fig. 6(b) and (c):

In Fig. 6(a): Within the variation range of hydraulic loops, the variation range of output pitch angle caused by the hydraulic loop in big arm is $\left[-43.99^{\circ}, 26.8^{\circ}\right]$. That by the hydraulic loop in small arm is $\left[-25.09^{\circ}, 83.2^{\circ}\right]$, and that by the hydraulic loop in executive end is $\left[-57.85^{\circ}, 52.91^{\circ}\right]$. Obviously, among the three hydraulic control loops, the hydraulic control loop of the executive end has the greatest influence on the output pitch angle, then the hydraulic loop of small arm. The influence of the hydraulic loop of big arm is the least.

In Fig. 6(b): Within the variation range of hydraulic loops, the variation range of output posture in Y-direction caused by the hydraulic loop in big arm is $[-859,806.9] \mathrm{mm}$. That in the small arm is $[106,144.2] \mathrm{mm}$. That by the swinging hydraulic loop is $[-9.953,1.732] \mathrm{mm}$ and that in the executive end is $[-186.7$, $526.1] \mathrm{mm}$. Therefore, we can conclude that the hydraulic loop in big arm has the greatest influence on the output posture in Ydirection.

Similarly, as shown in Fig. 6(c): The variation range of output posture in Z-direction caused by the hydraulic loop in big arm is $[311.6,62.02] \mathrm{mm}$. That by the hydraulic loop in small arm is $[-398.7,637.5] \mathrm{mm}$. That by the hydraulic loop in executive end is $[-227.27,108.1] \mathrm{mm}$, and that by the 


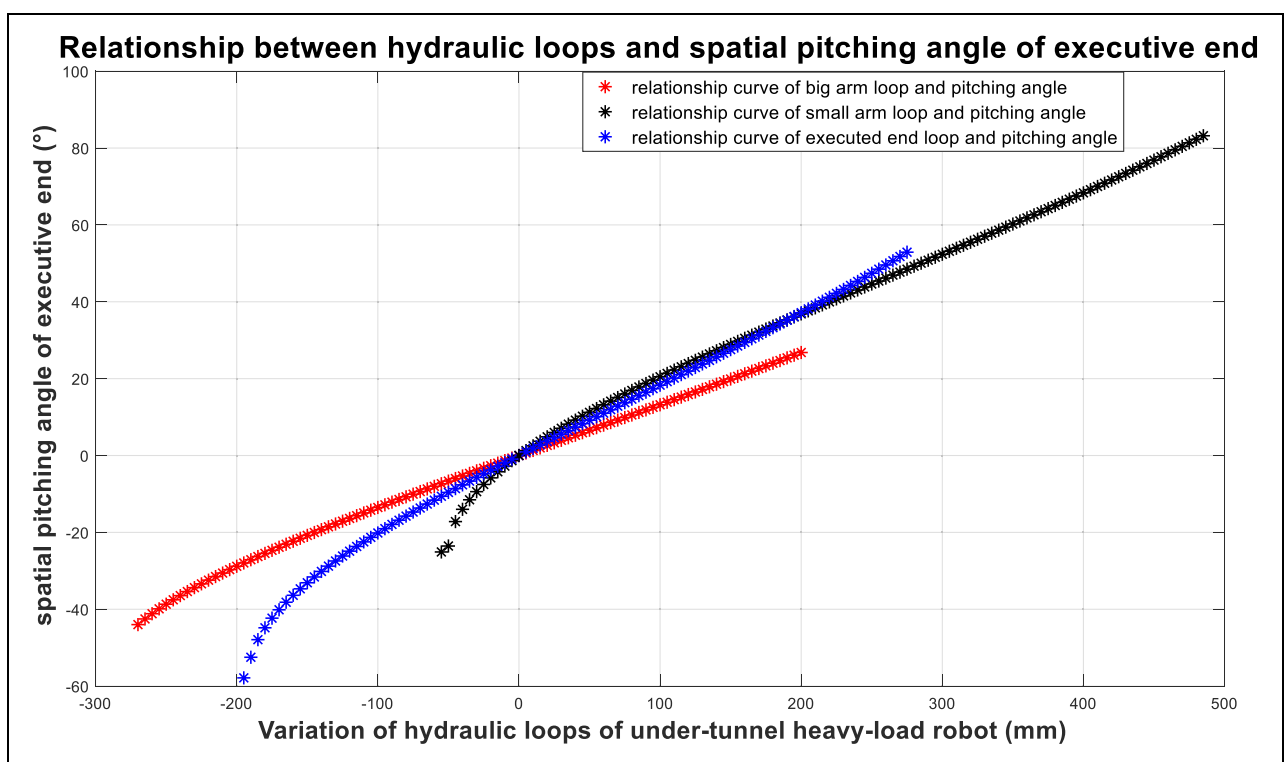

(a)

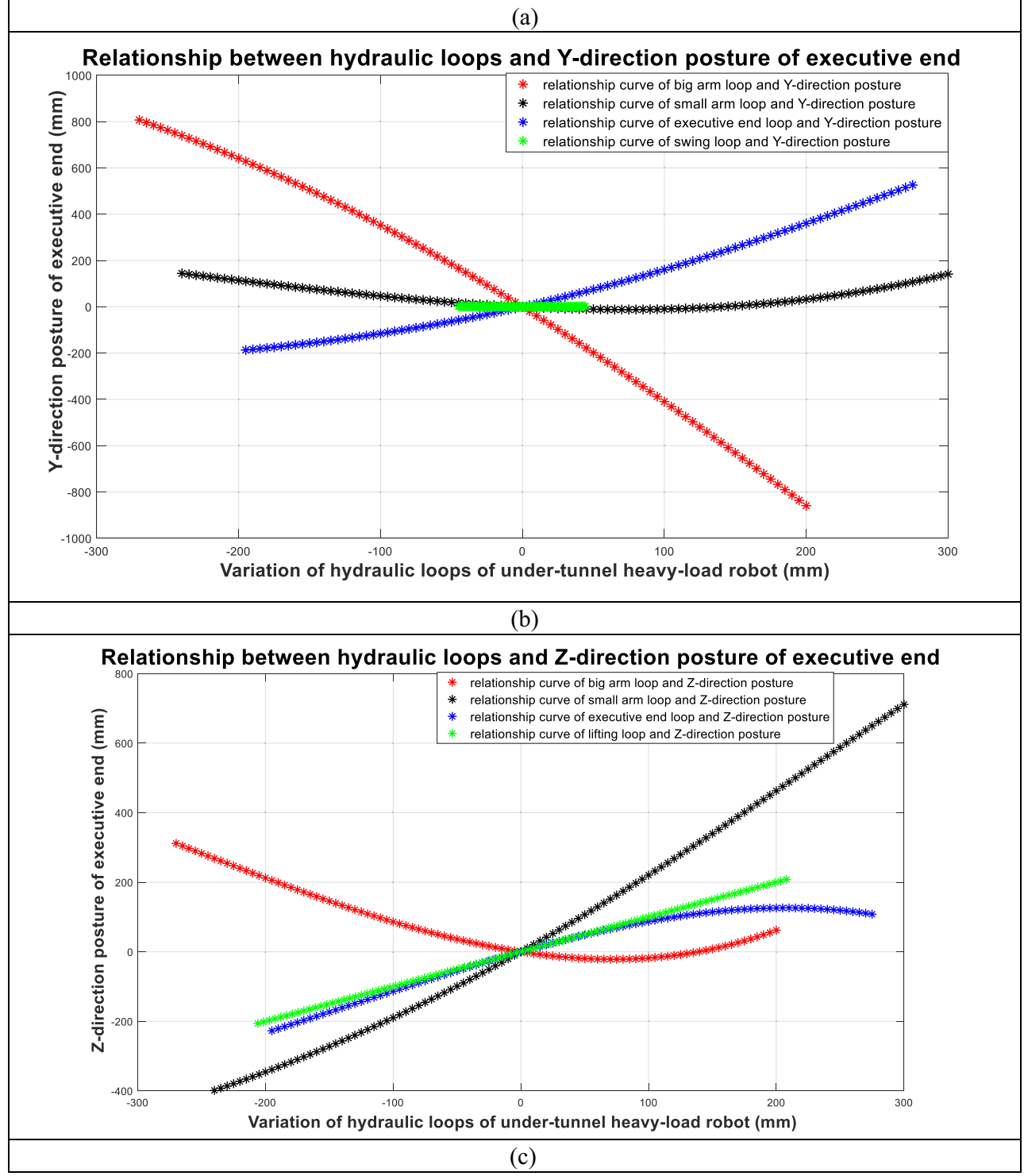

Fig. 6 Relationship between hydraulic loops and spatial posture of the executive end 
hydraulic loop in lifting platform is $[-206,208] \mathrm{mm}$, which means the hydraulic loop in small arm has the greatest influence on the output posture in Z-direction.

Combining Fig. 5 and the simulation results of Fig. 6 , we can see that the influence of each hydraulic loop on output spatial posture of the robot is quite different. Meanwhile, due to the influence of external environment, the actual system of the robot changes randomly during working process. Obviously, how to coordinate these random changes of subsystem dynamically is important for realizing the cooperation of MDO system for the underground heavy-load robot. Hence according to the Monte Carlo method [17, 18], the spatial posture coefficient matrix $K_{i j}$ is introduced to describe the influence of hydraulic loop $i(i=1,2,3,4,5,6)$ on output posture function $\mathrm{Y}(\mathrm{j})(\mathrm{j}=X, Y, Z, \alpha, \beta, \gamma)$ of the executive end qualitatively [19]:

$$
K_{i j}=\frac{\frac{1}{n} \sum_{i=1}^{n} Y_{i}(j)}{\frac{1}{n} \sum_{i=1}^{n} \widehat{Y}_{i}(j)}=\frac{\bar{Y}_{i}(j)}{\overline{\widehat{Y}}_{i}(j)}
$$

Where $K_{i j}$ is a $6^{*} 6$ spatial matrix; $K_{i j} \in[0,1](i=1,2,3,4,5,6)$ is the hydraulic loop of the robot as shown in Fig. $4 ; j=$ $1,2,3,4,5,6$ represents the each output spatial posture function of the executive end respectively; $n$ is the times of measurement; $Y_{i}(j)$ is the actual spatial posture function of hydraulic loop $i$, and $\widehat{Y}_{i}(j)$ is the planned spatial posture function of hydraulic loop $i$.

For considering the dynamical changes of friction and other dissipative factors of the hydraulic control loops, the posture coefficient $K_{i j}$, which is calibrated regularly according to the actual state of the robot, can accurately reflect the influence of each single hydraulic control loop on actual output spatial posture of the executive end. When each posture coefficient $K_{i j}$ is substituted into the actual posture function, the spatial posture of the executive end can be precisely expressed as:

$$
\left\{\begin{array}{l}
Y(X)=K_{21} Y(\alpha)+K_{31} Y(\gamma) \\
Y(Y)=K_{22} Y\left(Y_{2}\right)+K_{42} Y\left(Y_{4}\right)+K_{52} Y\left(Y_{5}\right)+K_{62} Y\left(Y_{6}\right) \\
Y(Z)=K_{13} Y\left(Z_{1}\right)+K_{33} Y\left(Z_{3}\right)+K_{43} Y\left(Z_{4}\right)+K_{53} Y\left(Z_{5}\right)+K_{63} Y\left(Z_{6}\right) \\
Y(\alpha)=K_{24} Y(\alpha) \\
Y(\beta)=K_{45} Y\left(\beta_{4}\right)+K_{55} Y\left(\beta_{5}\right)+K_{65} Y\left(\beta_{6}\right) \\
Y(\gamma)=K_{36} Y(\gamma)
\end{array}\right.
$$

The calibration method of $K_{i j}$ is as follows. Firstly, each hydraulic loop of the underground heavy-load robot is controlled to work separately with its maximum stroke $Y_{i}(j)$ in turn under no-load condition. Then, each total posture function item $\sum Y_{i}(j)$ is recorded. Finally, according to Monte Carlo method and sample weighting technique, the experimental data are analyzed, then the specific value of posture coefficient $K_{i j}$ can be obtained as:

$K_{6 \times 6}=\left[\begin{array}{cccccc}0 & 0 & 0.1878 & 0 & 0 & 0 \\ 0.7307 & 0.2183 & 0 & 0.8095 & 0 & 0 \\ 0.2693 & 0.2452 & 0.0397 & 0.1905 & 0 & 0.9815 \\ 0 & 0.2077 & 0.8203 & 0 & 0.4204 & 0 \\ 0 & 0.9812 & 0.1704 & 0 & 0.5706 & 0 \\ 0 & 0.007 & 0.1057 & 0 & 0.5513 & 0\end{array}\right]$

Take $K_{i 3}$ as an example: The posture coefficients of hydraulic loop 1, 2, 3, 4, 5, 6 to output spatial posture of the executive end in Z-direction are: $K_{13}=0.1878, K_{23}=0, K_{33}=$ $0.0397, K_{43}=0.8203, K_{53}=0.1704, K_{63}=0.1057$. Where: $K_{23}=0$ is the minimum value, indicating that the swing hydraulic loop 2 has no influence on the posture of the executive end in Z-direction, which is completely consistent with the actual working situation. Meanwhile, the maximum value is $K_{43}=0.8203$, which means the hydraulic loop 4 has the greatest influence on the output posture of the executive end in Z-direction, while spatial Z-posture of the executive end directly affects the maximum unloading distance and working height of the robot. This conclusion is consistent not only with the simulation results of Fig. 5(c), but also with the analyzed result of Reference [16], which can provide an effective basis for implement and precise control of the executive end of the underground heavy-load robot .

\subsection{DCO Design of MDO System for the Underground Heavy-Load Robot}

To weaken the strong coupling relationships among hydraulic executive loops becomes the key point to accurately control the final output spatial posture of the underground heavy-load robot. At present, the approach can be divided as direct decoupling method and coupling-reducing decoupling method. The direct decoupling method uses decoupling matrixes to decouple coupling systems according to the state feedback [20]. While, the couplingreducing decoupling method decouples the complex coupling system into many independent systems, and then designs the controller of each single system respectively, finally couples the independent systems as a whole [21].

Meshed with the idea of coupling-reducing decoupling method, a dynamic collaborative optimization (DCO) control algorithm is proposed in this paper: Firstly, according to the idea that hierarchical target transmission [22], the MDO system can be decomposed into a vertical motion control system and a horizontal motion control system, to reduce the coupling degree between subsystems and the corresponding spatial motion control models can also be constructed. Secondly, based on the small disturbance theory [23], a double-layer feedback control system is constructed, in which the primary motion is chosen as the external control loop and the auxiliary motion is the internal control loop. At the same time, to obtain precise control signals of each loop, the spatial posture coefficient is introduced to collaboratively allocate the sequence and flow 
of each hydraulic loop, and finally realize the dynamic optimal control of whole complex MDO system for the underground heavy-load robot.

According to the structural optimal model (2) of the underground heavy-load robot, the DCO optimal control system can be deduced as:

$\sum Q_{i j}=\sum\left[K_{i j}\right]\left(\left[\begin{array}{ll}W_{Z} & W_{H}\end{array}\right]\left[\begin{array}{c}Q_{Z} \\ Q_{H}\end{array}\right]\right)$

Where: $Q_{i j}$ is the control flow of hydraulic system; $\left[W_{Z}\right.$ $W_{H}$ is the spatial posture matrix of vertical and horizontal motion space; $\left[Q_{Z} Q_{H}\right]^{T}$ is the control flow matrix of vertical/horizontal motion control system.

\subsubsection{DCO Control of Vertical Motion Space}

(1) Dynamic posture model of vertical motion space

A c cording to Fig. 5, the posture $W_{V}\left(W_{V}=\left[Y_{V}(Y), Y_{V}(Z), Y_{V}(\beta)\right]^{\mathrm{T}}\right)$ of vertical motion space is implemented by the movements of hydraulic loop 1 in the lifting platform, hydraulic loop 4 in the big arm, hydraulic loop 5 in the small arm and hydraulic loop 6 in the executive end. Therefore, the posture function of the executive end in vertical motion space can be expressed:

$$
\left\{\begin{array}{l}
Y_{V}(Y)=Y_{V}\left(Y_{4}\right)+Y_{V}\left(Y_{5}\right)+Y_{V}\left(Y_{6}\right) \\
Y_{V}(Z)=Y_{Z}\left(Z_{1}\right)+Y_{V}\left(Z_{4}\right)+Y_{V}\left(Z_{5}\right)+Y_{V}\left(Z_{6}\right) \\
Y_{V}(\beta)=Y_{V}\left(\beta_{4}\right)+Y_{V}\left(\beta_{5}\right)+Y_{V}\left(\beta_{6}\right)
\end{array}\right.
$$

Where $Y_{\mathrm{V}}\left(Y_{i}\right)$ and $Y_{\mathrm{V}}\left(Z_{i}\right)$ are the $\mathrm{Y}$-direction and $\mathrm{Z}$ direction displacement functions of the executive end in vertical motion space. $\mathrm{Y}_{\mathrm{V}}\left(\beta_{i}\right)$ is the pitching angle function in vertical motion space. And $Y_{\mathrm{V}}\left(\beta_{i}\right), Y_{\mathrm{V}}\left(Y_{i}\right)$, and $Y_{\mathrm{V}}\left(Z_{i}\right)$ can be deduced according to the mechanical geometry of the hydraulic loops:

The $Y$-direction displacements of the big arm, small arm and executive end of hydraulic loops are:

$$
\left\{\begin{array}{l}
Y_{V}\left(Y_{4}\right)=L_{b} \cos \left(\frac{\pi}{2}+\beta_{4}-\frac{21.8 \pi}{180}\right)-L_{b} \cos \left(\frac{\pi}{2}+\beta_{40}-\frac{21.8 \pi}{180}\right) \\
Y_{V}\left(Y_{5}\right)=L_{s} \cos \left(\beta_{5}-\frac{43.39 \pi}{180}\right)-L_{s} \cos \left(\beta_{50}-\frac{43.39 \pi}{180}\right) \\
Y_{V}\left(Y_{6}\right)=L_{\mathrm{e}} \cos \left(\beta_{6}-\frac{83.48 \pi}{180}\right)-L_{e} \cos \left(\beta_{60}-\frac{83.48 \pi}{180}\right)
\end{array}\right.
$$

Similarly, the Z-direction displacements of the big arm, small arm and executive end of hydraulic loops can be obtained:

$$
\left\{\begin{array}{l}
Y_{V}\left(Z_{4}\right)=L_{b} \sin \left(\frac{\pi}{2}+\beta_{4}-\frac{21.8 \pi}{180}\right)-L_{b} \sin \left(\frac{\pi}{2}+\beta_{40}-\frac{21.8 \pi}{180}\right) \\
Y_{V}\left(Z_{5}\right)=L_{S} \sin \left(\beta_{5}-\frac{43.39 \pi}{180}\right)-L_{s} \sin \left(\beta_{50}-\frac{43.39 \pi}{180}\right) \\
Y_{V}\left(Z_{6}\right)=L_{\mathrm{e}} \sin \left(\beta_{6}-\frac{83.48 \pi}{180}\right)-L_{e} \sin \left(\beta_{60}-\frac{83.48 \pi}{180}\right)
\end{array}\right.
$$

Where $\quad \beta_{40}$ is the initial pitch angle of big arm $\left(^{\circ}\right) . \beta_{4}$ is the actual pitch angle of big arm $\left(^{\circ}\right)$.

$L_{\mathrm{b}} \quad$ is the effective working length of big $\operatorname{arm}\left(L_{\mathrm{b}}=\right.$ $L_{\mathrm{AA} 3}=1974.87 \mathrm{~mm}$ ).

$\Delta l_{\mathrm{b}} \quad$ is the change of the hydraulic loop in big arm $(\mathrm{mm}) . \beta_{50}$ is the initial pitch angle of small arm $\left(^{\circ}\right)$.

$\beta_{5} \quad$ is the actual pitch angle of small $\operatorname{arm}\left({ }^{\circ}\right)$.

$L_{\mathrm{s}} \quad$ is the effective working length of small arm (mm) $\left(L_{\mathrm{S}}=L_{\mathrm{BB} 4}=1074.66 \mathrm{~mm}\right)$

$\Delta l_{\mathrm{s}} \quad$ is the change of the hydraulic loop in small arm (mm).

$\beta_{60} \quad$ is the initial pitch angle of executive end $\left(^{\circ}\right) . \beta_{6}$ is the actual pitch angle of executive end $\left(^{\circ}\right)$.

$L_{\mathrm{e}} \quad$ is the effective working length of executive end $\left(L_{\mathrm{M}}=L_{\mathrm{B} 3 \mathrm{D}}=626.15 \mathrm{~mm}\right)$

$\Delta l_{\mathrm{e}} \quad$ is the change of executive end (mm)

The pitch angle of corresponding actuator arm is: $Y_{V}\left(\beta_{i}\right)=\arctan \frac{Y_{V}\left(Z_{i}\right)}{Y_{V}\left(Y_{i}\right)}$

(2) DCO control of vertical motion space.

The vertical motion system controls the posture of the robot in YOZ plane by adjusting the flow of corresponding hydraulic loops, and then the DCO control model of vertical motion space can be constructed:

$\sum Q_{V}=\sum Q_{V Y}+\sum Q_{V Z}+\sum Q_{V \beta}$

$=K_{V Y} \sum Y_{V}(Y) \times\left[Q_{V Y}\right]+K_{V Z} \sum Y_{V}(Z) \times\left[Q_{V Z}\right]+K_{V \beta} \sum Y_{V}(\beta) \times\left[Q_{V \beta}\right]$

Where: $\sum Q_{\mathrm{V}}$ is the total control flow of vertical motion space. $\mathrm{K}_{\mathrm{VY}}$ is the $\mathrm{Y}$-direction posture coefficient of executive end in vertical motion space $\left(K_{\mathrm{VY}}=\left[K_{22}, K_{42}, K_{52}\right]\right) . K_{\mathrm{VZ}}$ is the Zdirection posture coefficient of executive end in vertical motion space $\left(K_{\mathrm{VZ}}=\left[K_{13}, K_{43}, K_{53}\right]\right) . K_{\mathrm{V} \beta}$ is the pitch-angle posture coefficient of executive end in vertical motion space $\left(K_{V \beta}=\left[K_{44}, K_{54}, K_{64}\right]\right)$.

Then according to the analytical target cascading (ATC) theory, we can construct the DCO control model of vertical motion space as shown in Fig. 7. Because the Z-direction motion is the main operation motion of the executive end, the Z-direction displacement is chosen as external primary feedback loop, meanwhile the pitch-angle and Y-direction are chosen as the inner auxiliary feedback loops. At the same time, the logical order of hydraulic loops is allocated according to the value of posture coefficient $K_{\mathrm{ij}}$.

Then the DCO control flow of vertical motion space system can be obtained by substituting the connection modes of hydraulic loops:

$\sum Q_{V}=\sum Q_{V Y}+\sum Q_{V Z}+\sum Q_{V \beta}$ 


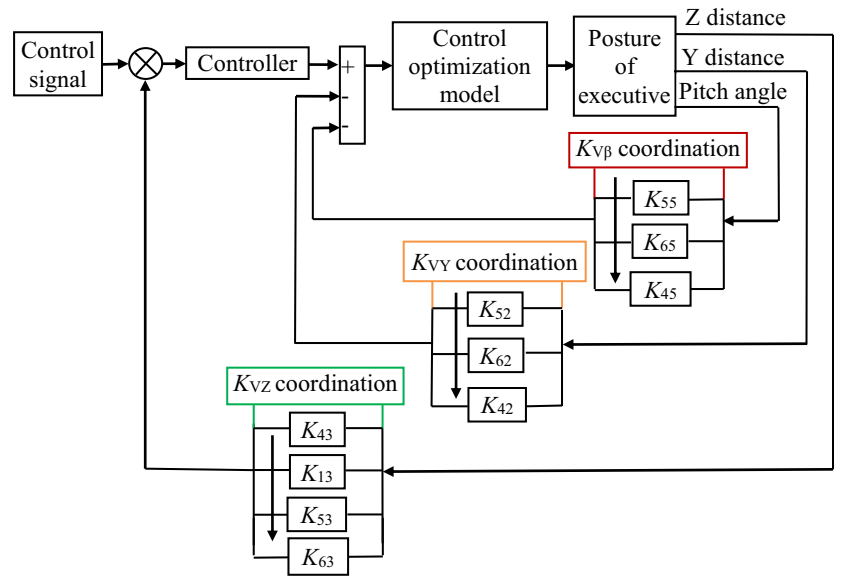

Fig. 7 DCO control system of vertical motion space

Where:

$$
\begin{aligned}
& \sum Q_{V Y}=\sum C_{q} w_{s} \sqrt{\frac{2}{\rho}(\Delta P)}\left[K_{22} K_{42} K_{52}\right] \\
& \sum Q_{V Z}=\sum C_{q} w_{s} \sqrt{\frac{2}{\rho}(\Delta P)}\left[K_{13} K_{43} K_{53}\right] \\
& \sum Q_{V \beta}=\sum C_{q} w_{s} \sqrt{\frac{2}{\rho}(\Delta P)}\left[K_{45} K_{55} K_{65}\right]
\end{aligned}
$$

\subsubsection{DCO Control of Horizontal Motion Space}

(1) Dynamic posture model of horizontal spatial motion

The output posture of executive end in horizontal XOY space is completed by swinging and rotating of turntable hydraulic loops. Therefore, the spatial posture of executive end i n horizontal s p a e i s : $W_{H}=\left[\mathrm{Y}_{H}(X), Y_{H}(Y), Y_{H}(Z), Y_{H}(\alpha), Y_{H}(\gamma)\right]^{\mathrm{T}}$. The corresponding posture function of executive end is:

$$
\left\{\begin{array}{l}
Y_{H}(X)=Y_{H}\left(X_{2}\right)+Y_{H}\left(X_{3}\right) \\
Y_{H}(Y)=Y_{H}\left(\mathrm{Y}_{2}\right)+Y_{H}\left(Y_{3}\right) \\
Y_{H}(Z)=Y_{H}\left(Z_{3}\right) \\
Y_{H}(\alpha)=Y_{H}\left(\alpha_{2}\right) \\
Y_{H}(\gamma)=Y_{H}\left(\gamma_{3}\right)
\end{array}\right.
$$

Where: $Y_{\mathrm{H}}(X), Y_{\mathrm{H}}(Y), Y_{\mathrm{H}}(Z)$ are the output displacement functions in $X$ direction, $Y$ direction and $Z$ direction of executive end in horizontal motion space respectively;

$Y_{\mathrm{H}}(\alpha)$ is the angular displacement function: $Y_{H}(a)=$ $2 \pi n_{2} L_{2} / 60$ ( $n_{2}$ is the swinging speed of turntable $(\mathrm{rad} / \mathrm{s}), L_{2}$ is the effective swinging radius $(\mathrm{mm})$ );

$Y_{H}(\gamma)$ is the rotational displacement function: $Y_{H}(\gamma)=$ $2 \pi n_{3} L_{3} / 60\left(Y_{\mathrm{H}(\gamma)} \in\left[-180^{\circ}, 180^{\circ}\right], n_{3}\right.$ is the rotation speed of rotary $\operatorname{table}\left(n_{3}=0.034 \mathrm{rad} / \mathrm{s}\right), L_{3}$ is the effective length of rotating $\operatorname{arm}\left(L_{3}=4405 \mathrm{~mm}\right)$ );

\section{(2) DCO control of horizontal motion space}

The motion of horizontal space is realized by the swinging and rotating motions of the whole executive arm, hence the DCO control model of the horizontal motion space is:

$$
\begin{aligned}
\sum Q_{H}= & K_{H X} \sum Y_{H}(X)\left[Q_{H X}\right]+K_{H Y} \sum Y_{H}(Y)\left[Q_{H Y}\right] \\
& +K_{H Z} \sum Y_{H}(Z)\left[Q_{H Z}\right]+K_{H a} \sum Y_{H}(a)\left[Q_{H a}\right] \\
& +K_{H \gamma} \sum Y_{H}(\gamma)\left[Q_{H \gamma}\right]
\end{aligned}
$$

Where: $\sum Q_{H}$ is the total flow of horizontal space; $K_{H X}$ is the $X$-direction posture coefficient in horizontal space $\left(K_{H X}=\left[K_{21}, K_{31}\right]\right) ; K_{H Y}$ is the $Y$-direction posture coefficient in horizontal space $\left(K_{H Y}=\left[K_{22}, K_{32}\right]\right) ; K_{H Z}$ is the $Z$-direction posture coefficient in horizontal space; $K_{H \alpha}$ is the horizontal deflection angle coefficient in horizontal space $\left(K_{H \alpha}=\left[K_{24}\right]\right)$; $K_{H \gamma}$ is the transverse angle coefficient in horizontal space $\left(K_{H \gamma}=\left[K_{36}\right]\right)$.

Similarly, the $Y / Z$ direction displacement $Y_{\mathrm{HY}} / Y_{\mathrm{HZ}}$ and $X$ direction displacement $Y_{\mathrm{HX}}$ of executive end are chosen as internal auxiliary feedback loops, while the deflection angle $Y_{\mathrm{H}(\alpha)} / Y_{\mathrm{H}(\gamma)}$ is as external primary loop. Then the DCO control system of horizontal motion space is constructed in Fig. 8.

In Fig. $8, K_{\mathrm{HL}}$ is the length coefficient of executive arm (when the executive arm swings: $K_{\mathrm{HL}}=L_{\mathrm{Z}} /\left(L_{\mathrm{Z}}+L_{23}+L_{34}\right)$; when the executive arm rotates: $\left.K_{\mathrm{HL}}=L_{\mathrm{Z}} /\left(L_{\mathrm{Z}}+L_{34}\right)\right)$. $L_{\mathrm{Z}}$ is the effective working length of executive end.

Finally, according to Fig. 8 the DCO control flow of horizontal motion space can be obtained:

$\sum Q_{H}=\sum Q_{H X}+\sum Q_{H Y}+\sum Q_{H Z}+\sum Q_{H \alpha}+\sum Q_{H \gamma}$

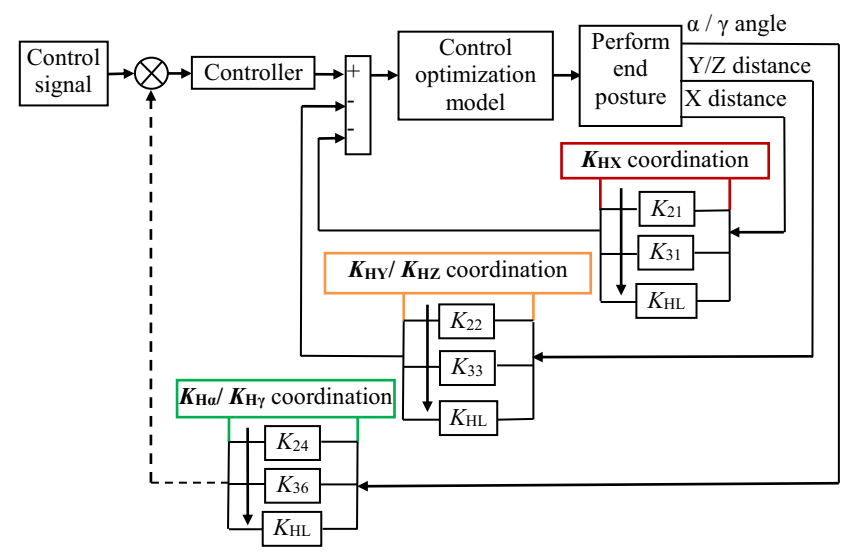

Fig. 8 DCO control system of horizontal motion space 
Where:

$$
\begin{aligned}
& \sum Q_{H Y}=\sum C_{q} w_{s} \sqrt{\frac{2}{\rho}(\Delta P)}\left[K_{22} K_{H L}\right] \sin \left(\frac{2 \pi n_{2}}{60}\right) \\
& \sum Q_{H Z}=\sum C_{q} w_{s} \sqrt{\frac{2}{\rho}(\Delta P)\left[K_{33} K_{H L}\right] \sin \left(\frac{2 \pi n_{3}}{60}\right)} \\
& \sum Q_{H \alpha}=C_{q} w_{s} \sqrt{\frac{2}{\rho}(\Delta P)} K_{24} \times \frac{2 \pi n_{2}}{60} \\
& \sum Q_{H \gamma}=C_{q} w_{s} \sqrt{\frac{2}{\rho}(\Delta P) K_{36} \times \frac{2 \pi n_{3}}{60}}
\end{aligned}
$$

According to the planned output posture trajectory of executive end, the precise adjusting and collaborative control for action sequence of each hydraulic loop can be obtained quickly by applying the DCO control algorithm. Moreover, the DCO control algorithm also can avoid the lagged effect of interactive coupling of MDO control system.

\section{Experiments and Simulation}

Take underground heavy-load robot $30 / 400$ as experimental entity, and apply mining intrinsic safety control converter KZC12 developed by Chongqing safe Science and Technology Co., Ltd. (other measuring instruments are omitted here), as shown in Fig. 9.

The actual effect of DCO method is tested by PTP (point to point) [24] servo control experiment of vertical motion space, and the trajectory fitting accuracy of DCO method is tested by continuous path servo control experiment of horizontal motion space.

\subsection{Simulation and Experiment of Vertical Motion Space}

The PTP (point-to-point) control experiment in vertical motion space is: The executive end was adjusted to move from spatial point A $(-29.4,-1892,1158)$ to spatial point B $(-29.4,-4417,-336.1)$, then the actuator started to preset heavy-load operation.

The specific situational and experimental process is: The lifting platform hydraulic cylinder was lowered by $\Delta l_{1}=$ $201 \mathrm{~mm}$; The big arm hydraulic cylinder was retracted by $\Delta l_{4}=460 \mathrm{~mm}$; The small arm hydraulic cylinder was retracted by $\Delta l_{5}=520 \mathrm{~mm}$ and the executive end hydraulic cylinder was retracted by $\Delta l_{6}=310 \mathrm{~mm}$. The situational spatial posture trajectory of the executive end is shown in Fig. 10(a) and actual experimental spatial trajectory is shown in Fig. 10(b) with red curve.

The speeds of hydraulic cylinders are: $v_{1 \mathrm{~d}}=201 \mathrm{~mm} / \mathrm{s}$, $v_{2 \mathrm{~d}}=255 \mathrm{~mm} / \mathrm{s}, v_{4 \mathrm{~d}}=255 \mathrm{~mm} / \mathrm{s}, v_{5 \mathrm{~d}}=256 \mathrm{~mm} / \mathrm{s}$ and $v_{6 \mathrm{~d}}=$ $257 \mathrm{~mm} / \mathrm{s}$. Therefore, the total executive time of the system is: $\sum t_{\mathrm{v}=} t_{1 \mathrm{~d}}+t_{4 \mathrm{~d}}+t_{5 \mathrm{~d}}+t_{6 \mathrm{~d}}=6.146(\mathrm{~s})$. According to Eq. (4), the total control flow of the executive hydraulic loop is: $\sum Q_{V}=Q_{1}+Q_{4}+Q_{5}+Q_{6}=44.944(L)$.

The optimal process of DCO method is: Firstly, the start and end conditions were introduced into dynamic collaborative optimal control model (2); Secondly, the execution action of each hydraulic loop was coordinated and optimized according to the posture coefficient $K_{i j}$, and the particle swarm optimal algorithm was used to solve the optimal solution under geometric and control constraints. The finally DCO results were: $\Delta l_{1}=108 \mathrm{~mm}, \Delta l_{4}=$ $216 \mathrm{~mm}, \Delta l_{5}=520 \mathrm{~mm}$ and $\Delta l_{6}=396 \mathrm{~mm}$. Then the collaborative optimal posture trajectory of executive end is shown with the blue curve in Fig. 10(b). The total executive time is: $\sum t_{V}=t_{1 d}+t_{4 d}+t_{5 d}+t_{6 d}=5.2763(s)$, and the t o t a $1 \quad$ c o n t r o l f l o w i s : $\sum Q_{V}=Q_{1}+Q_{4}+Q_{5}+Q_{6}=40.45(L)$
Fig. 9 Experimental equipment (a) underground heavy-load robot $30 / 400$, (b) safety converter $\mathrm{KZC} 12$

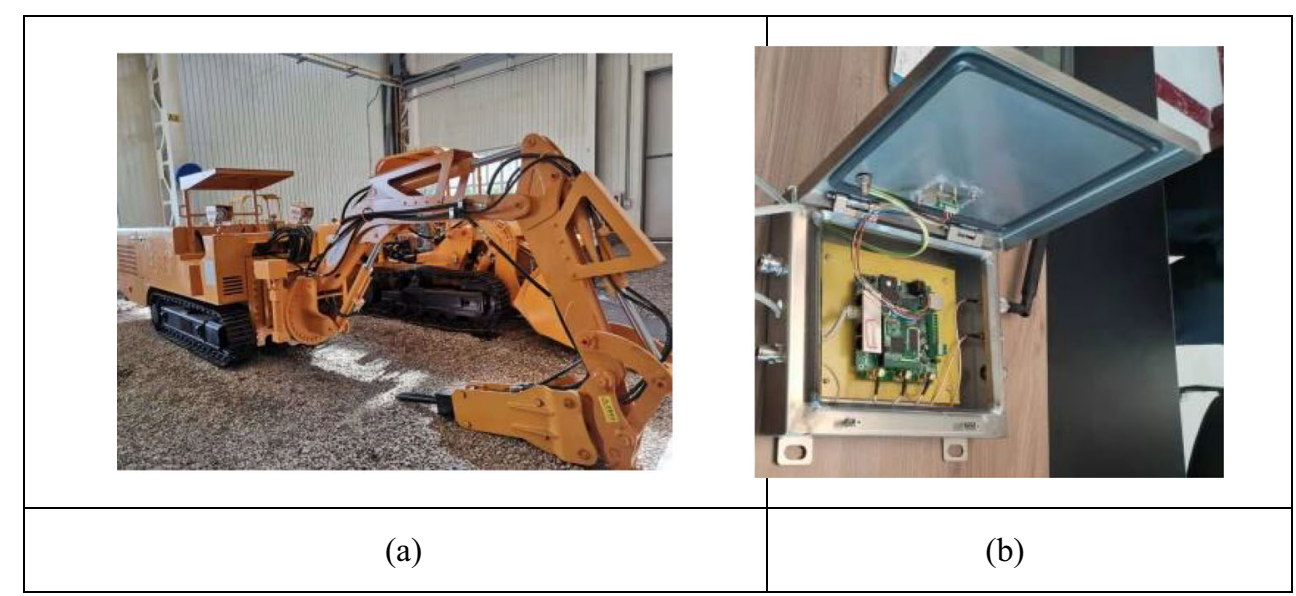




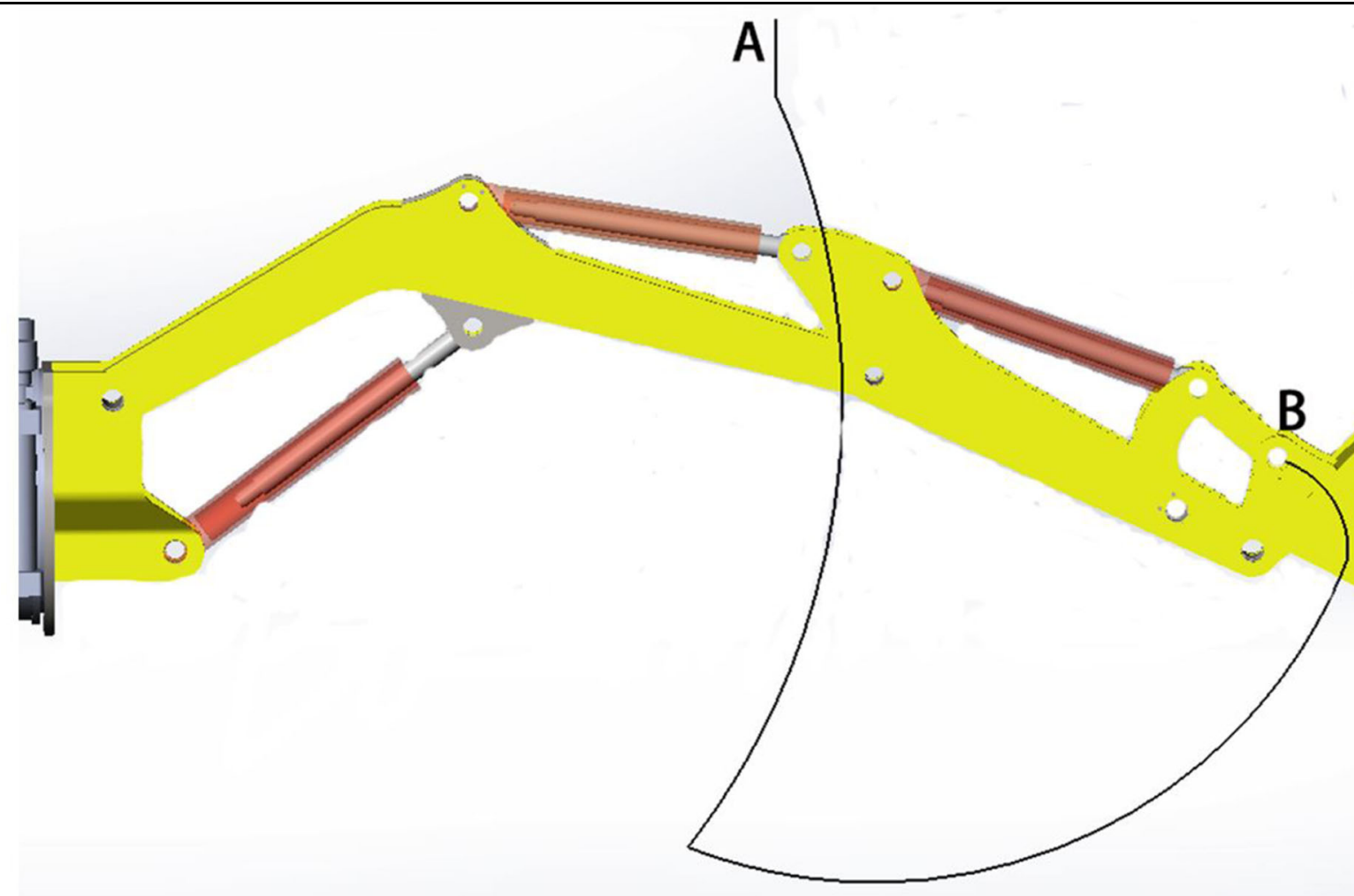

(a)

\section{The Posture trajectory of heavy-load robot in vertical space}

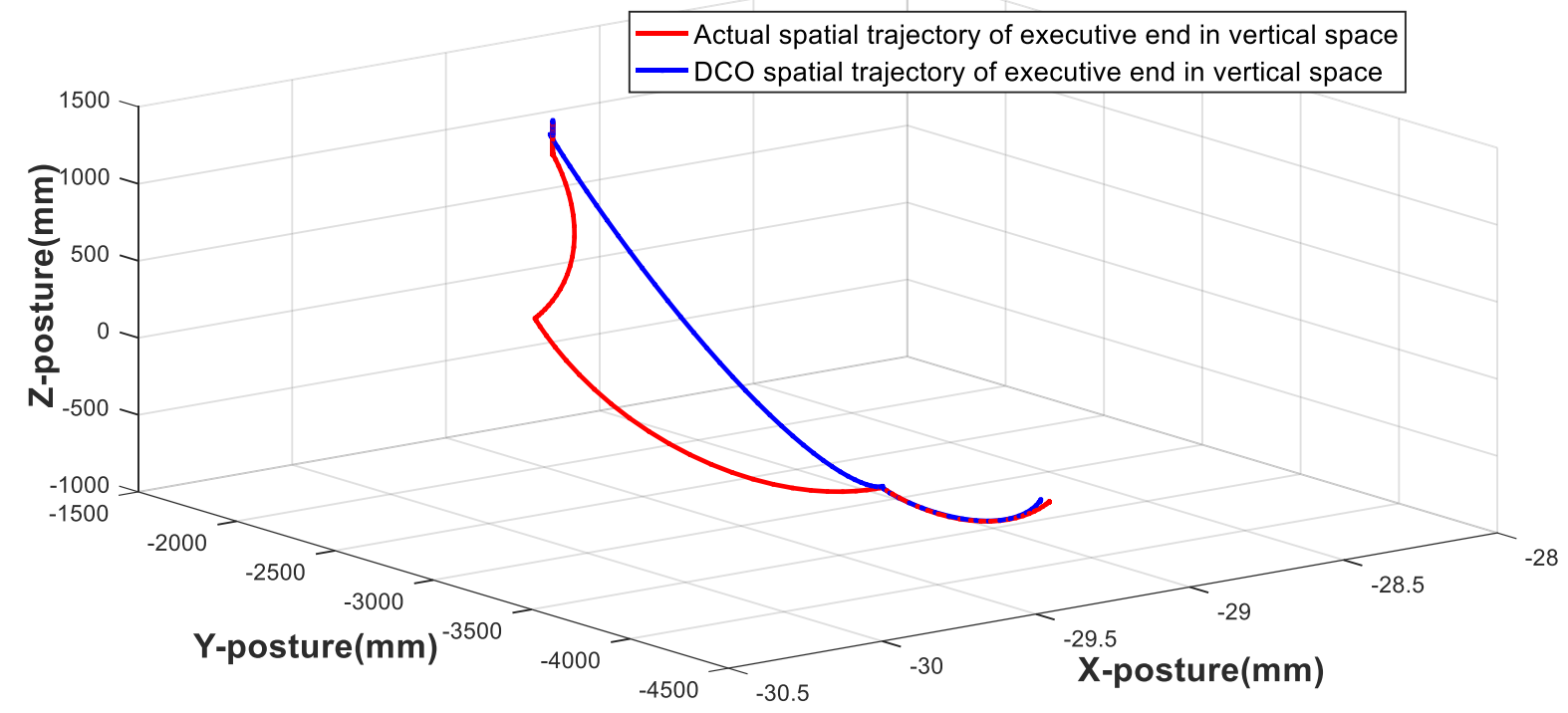

(b)

Fig. 10 The posture trajectory of executive end in vertical motion space. a Simulation posture trajectory of executive end in vertical motion space, $\mathbf{b}$ Posture trajectory of DOC in vertical space 
From the comparison, we can see that: After DCO control, the executive time of whole MDO system is saved by $\Delta t_{\mathrm{v}}=0.8697(\mathrm{~s})$, and the hydraulic flow is saved by $\Delta Q_{\mathrm{v}}=$ 4.494( $L)$. That means the executive efficiency of overall system is improved by $14.2 \%$ and the control flow is saved by $9.98 \%$.

\subsection{Simulation and Experiment of Horizontal Motion Space}

In order to verify the accuracy of DCO control algorithm, the continuous servo path motion in horizontal motion space is analyzed: Firstly, the lifting mechanism was descended by $\Delta l_{1}=210 \mathrm{~mm}$; turntable swung by 40 degrees and rotated by 90 degrees. The spatial motion trajectory curve of the

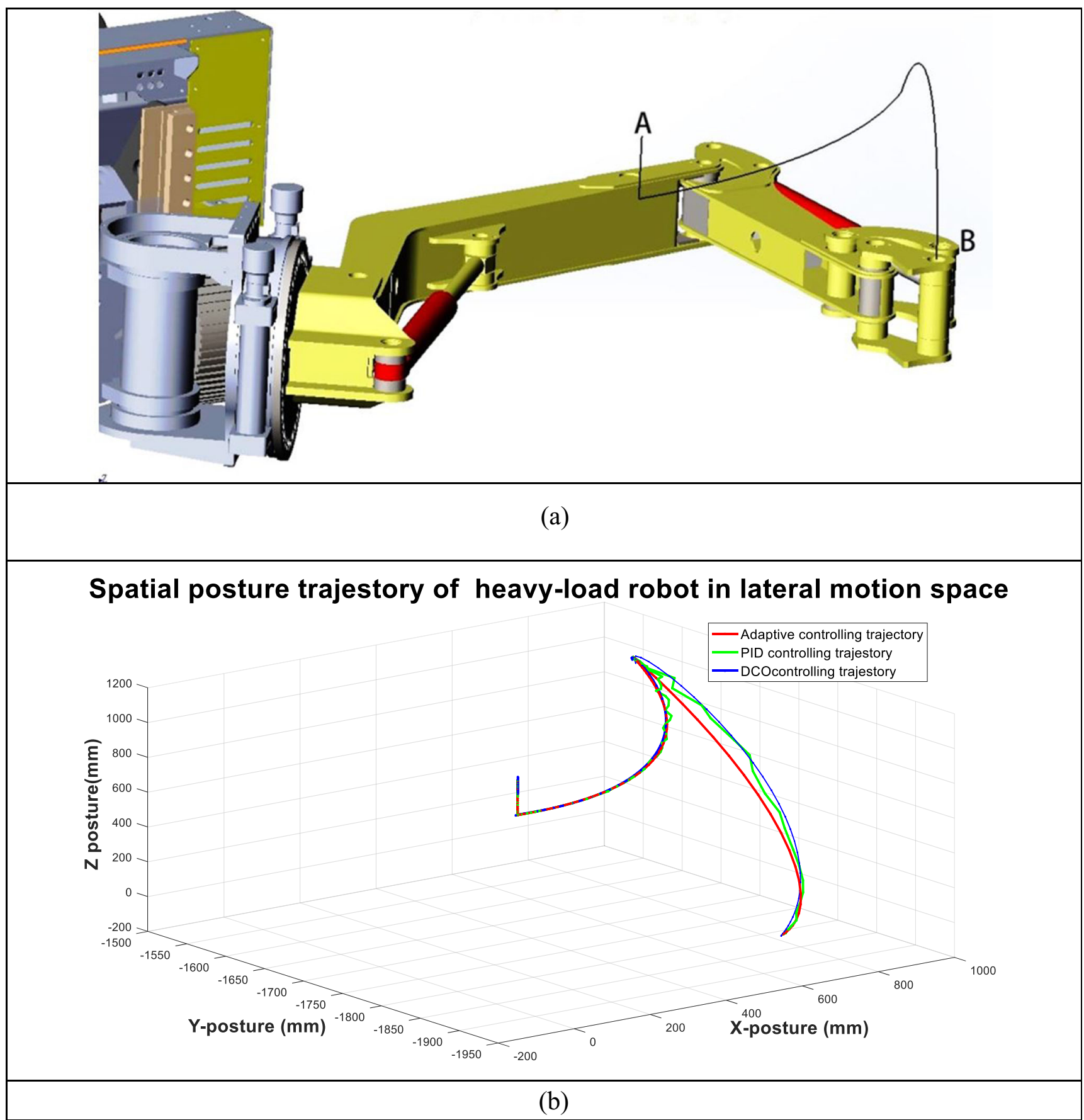

Fig. 11 The posture trajectory of executive end in horizontal motion space, (a) Simulation posture trajectory of executive end in horizontal motion space, (b) Posture trajectory of DOC in horizontal space 
Fig. 12 Comparison of RMSE in horizontal motion space

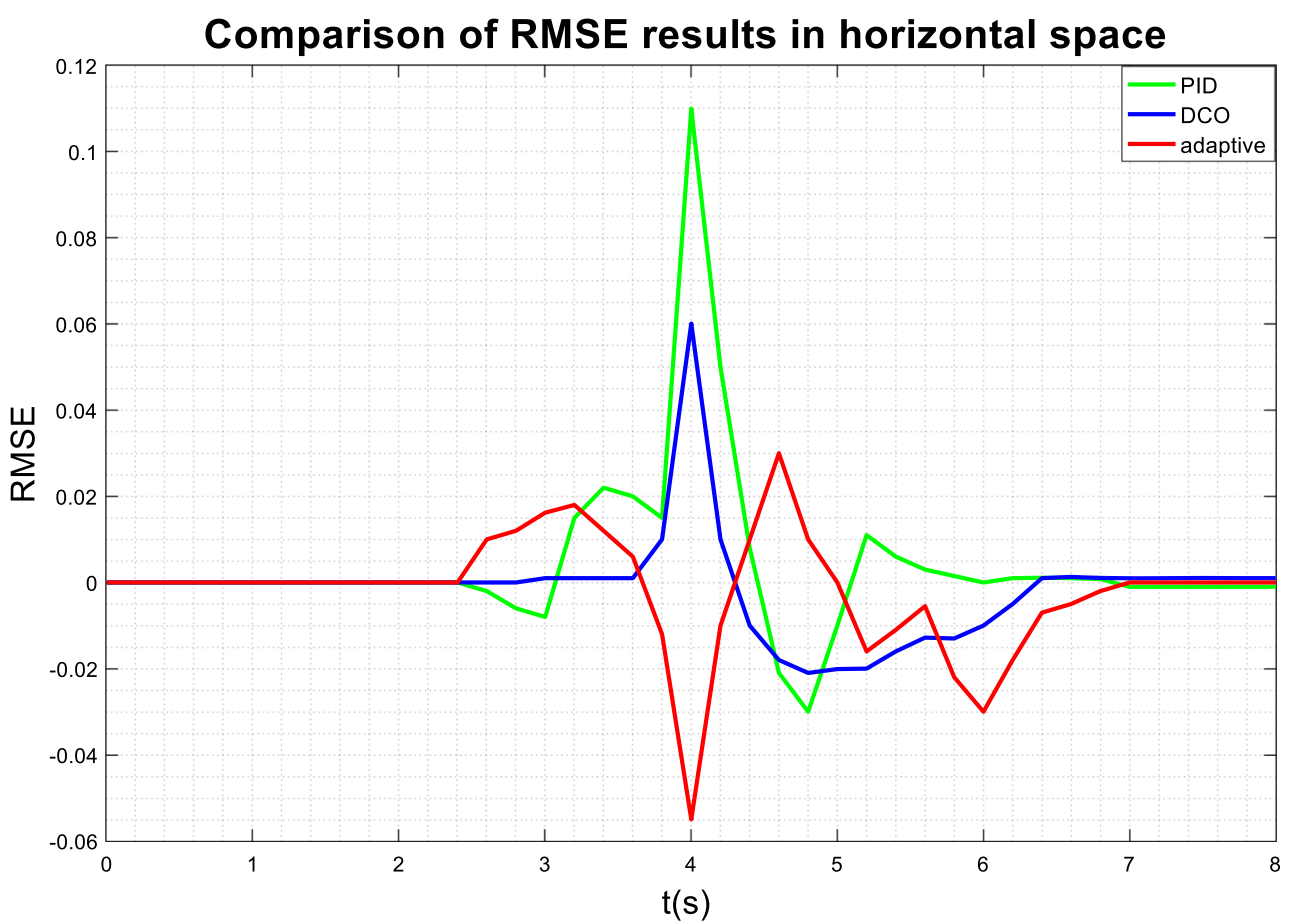

executive end is shown in Fig. 11(a). Similarly, the experimental comparison of posture trajectory in horizontal space controlled by adaptive algorithm, PID algorithm and DCO algorithm are shown in Fig. 11(b) respectively.

The SSE (sum of squares due to error) and RMSE (root mean square error) of regression system are used to verify the fitting accuracy between actual output spatial posture trajectory and spatial posture trajectory after DCO control of the executive end. The results are shown in Table 1:

The root mean square error (RMSE) of regression system is used to verify the fitting accuracy of each control algorithm:

$\delta_{W_{\text {RUSE }}}=\sum_{i=1}^{n} \sqrt{\left(\widehat{W}_{i}-W_{C i}\right)^{2} / n}$

Where: $\widehat{W}_{i}$ is the theoretical posture trajectory of the executive end; $W_{C i}$ is the actual posture trajectory of the executive end after adjusting; $\mathrm{n}$ is the number of measurements.

Then the comparison results of RMSE analysis for posture trajectory in horizontal space are shown in Fig. 12.

In Fig. 12, compared with adaptive algorithm and PID algorithm, the RMSE of DCO algorithm obviously convergences to zero and is more stable, which fully verifies that the DCO algorithm proposed in this paper not only has high fitting accuracy but also has superior transient regulatory performance and stability in spatial posture control of robots.

Based on the above simulation and experimental results, we can conclude that the DCO algorithm proposed in this paper has high performance and accuracy, and fully meets the high precise adjusting requirements for overall complex MDO system, in both the executive efficiency and the output trajectory fitting accuracy.

\section{Conclusions}

Based on the new developed intelligent underground heavyload robot, this paper proposes that the design of MDO system which is strongly coupled by mechanical, electrical and hydraulic engineering machinery, should avoid taking the structural design as the main factor, and ignoring the strong coupling among machinery, executive and control systems. Instead, we should solve this problem by modeling and control each part in parallel, dynamically and coordinately, and finally achieve the integrated design and collaborated control of overall complex MDO system.

The efficient DCO algorithm based on complex MDO system of the underground heavy-load robot is designed, by decoupling the strong coupling system and introducing the dynamic posture coefficient matrix, to realize the dynamic cooperative design of the whole MDO system of the underground heavy-load robot.

The DCO control algorithm proposed in this paper realizes the high efficiency, precision and fast response control system for the underground heavy-load robot, which can effectively make up the shortcomings of current design of MDO system products. And the DCO control algorithm also has high practical application and value in development of high precision control system 
for the same kind of complex intelligent engineering machinery products. Then, further research will be made on the DCO algorithm of task planning for underground heavy-load robots.

Acknowledgments This work was supported by the National Basic Research Program of China: Principle and method of intelligent measurement and control for walking, deviation correction and cutting accuracy of cantilever roadheader in coal mine (2018101060080).

Contributions Lixia Fang conceived and designed the study. Pengjiang Wang performed the simulation and experiments. Tong Wang and Chenxin Hou reviewed and edited the manuscript. Miao $\mathrm{Wu}$ reviewed the paper. All authors read and approved the manuscript.

Code Availability All code generated or used during the study are available from the corresponding author by request.

Data Availability The data used to support the findings of this paper are included within the article.

\section{Declarations}

Conflict of Interest The authors declare that they have no conflicts of interest.

Open Access This article is licensed under a Creative Commons Attribution 4.0 International License, which permits use, sharing, adaptation, distribution and reproduction in any medium or format, as long as you give appropriate credit to the original author(s) and the source, provide a link to the Creative Commons licence, and indicate if changes were made. The images or other third party material in this article are included in the article's Creative Commons licence, unless indicated otherwise in a credit line to the material. If material is not included in the article's Creative Commons licence and your intended use is not permitted by statutory regulation or exceeds the permitted use, you will need to obtain permission directly from the copyright holder. To view a copy of this licence, visit http://creativecommons.org/licenses/by/4.0/.

\section{References}

1. GAI, K., Yang, J.: Application analysis and development strategy of robot in coal industry. J. Beijing Institut. Technol. 17(2), 9-11 (2018)

2. Hassan, H., Simo, J., Crespo, A.: Flexible realtime mobile robotic architecture based on behavioural models. Engineering Applications of Artificial Intelligence. 14(5), 685-702 (2001)

3. Bai, X., Li, W.: Design optimization of complex mechanical system by collaborative optimization method. Mechanical Design. 23(3), 31-34 (2006)

4. Zhou, Q.: Multidisciplinary collaborative optimization algorithm based on dynamic penalty factor and its application in ship design. Ship Mechanics. 10, 1269-1280 (2016)

5. Zheng, A., Liu, R., et al.: Multi objective cooperative optimization of UAV based on genetic algorithm. Aircr. Des. 38(2), 11-15 (2018)
6. Li, W., Gao, L., Garg, A.: Multidisciplinary robust design optimization considering parameter and modelling uncertainties. Eng. Comput. (5), (2020). https://doi.org/10.1007/s00366-020-01046-3

7. Long, T., Liu, J., et al.: Development of multidisciplinary optimization design technology and its application in aerospace field. Aviation Manufacturing Technology. 3, 24-32 (2016)

8. Peng, L., Li, X., et al.: Development and application of multidisciplinary integrated optimization design for vehicle structure and performance. China Automotive Engineering in 2019 IEEE. (5), 401408 (2019)

9. Zhao, Y., Lu, Y., et al.: MDO strategy for meridian plane design to improve energy conversion capability of LFR main coolant pump. Ann. Nucl. Energy. 148, (2020). https://doi.org/10.1016/j.anucene. 2020.107763

10. Colette, M.: A goal-programming enchained collaborative optimization approach to reducing lifecycle costs for naval vessels. Structural and Multidisciplinary Optimization. 1-15 (2016)

11. Zhu, L.: Design of WPZ-45 / 350L multi-functional tunnel repair machine. China Coal. 42(3), 64-66 (2016)

12. Yan, L., Liu, H.: Research and development of multifunctional tunnel repair machine for coal mine. Mechanical engineering and automation. 208(3), 100-105 (2018)

13. Tappeta, R., Renaud, J.: Multi-objective collaborative optimization. ASME Journal of Mechanical Design. 29(3), 403-411 (1997)

14. Yi, Y.: Research on multidisciplinary design optimization method based on collaborative approximation and set strategy. Huazhong University of science and technology. (2019)

15. Peng, B.: Research on phased power matching technology of hydraulic excavator. Zhejiang University. (2016)

16. Li, B.: A strategic study on improving the efficiency design for hydraulic excavators. Zhejiang University. (2016)

17. Guo, L.: Research on trajectory planning of autonomous mining robot working device. Chang an University. (2017)

18. Li, G., Zhang, J., Chen, J., et al.: A monte carlo box localization. Algorithm Based on RSSI. 6, 1-11 (2014)

19. Li, K.: Research on mobile node location of wireless sensor network based on Monte Carlo. HuaDong University of technology. (2015)

20. Yang, Y.: Research on control strategy of multi DOF hydraulic servo system. Central South University. (2006)

21. Yi, Y., Li, W., Xiao, M., et al.: A set strategy approach for multidisciplinary robust design optimization under interval uncertainty. Advance in Mechanical Engineering. 1, 1-17 (2019)

22. Tan L, Damodaran M. Computational study of the flight dynamics stability and control of an unmanned aerial vehicle in an integrated simulation framework. AIAA Atmospheric Flight Mechanics conference and Exhibit. 10.2514/6.2008:1-17 (2008)

23. Gao Y, Zheng J, Jiang X. Multidisciplinary design integrated optimization method of fluid and structure based on hierarchical target transfer. Journal of Hubei University (NATURAL SCIENCE EDITION). (7):390-395 (2018)

24. Yang, Q., Ruan, Y., Zhang, J., et al.: Dynamic simulation analysis of heavy-load composite handling robot based on ADAMS. New industrialization. 3, 34-39 (2018)

Publisher's Note Springer Nature remains neutral with regard to jurisdictional claims in published maps and institutional affiliations. 
Lixia Fang Associate Professor, Major in Machinery Manufacturing and Automation, Master of Engineering, CPC Member. Mainly engaged in institutional design and research.

Tong Wang Associate Professor, Major in Machinery Manufacturing and Automation, Master of Engineering. Mainly engaged in mechanical design.

Pengjiang Wang was born in 1994. He is currently pursuing the Ph.D. degree with the School of Mechanical Electronic and Information Engineering, China University of Mining \& Technology (Beijing),
Beijing, China. His research interests include control of mining mechanical, electrical equipment and robot.

Chenxin Hou is a graduate student of China university of Mining \& Technology (Beijing), Beijing, China. His research interests include control of mining mechanical

Miao Wu Professor of Mechanical Electronic and Information Engineering, China University of Mining and Technology (Beijing). Mainly engaged in coal mechanism design and research. 